\title{
Analisis Faktor-Faktor yang Berhubungan dengan Tingginya Rujukan Kasus Non Spesialistik Pasien Jaminan Kesehatan Nasional pada Puskesmas di Kabupaten Sukabumi Tahun 2015
}

\author{
Analysis of Factors Related to the High Rate of Non-Specialist Referral for \\ National Health Insurance's Members in Sukabumi District Public Health Centers \\ in 2015
}

\author{
Masykur Alawi ${ }^{1}$, Purnawan Junadi ${ }^{2}$, Siti Nur Latifah ${ }^{3}$ \\ ${ }^{1}$ Program Studi Magister IImu Kesehatan Masyarakat Fakultas Kesehatan Masyarakat Universitas Indonesia, Depok \\ 2Departemen Administrasi Kebijakan Kesehatan, Fakultas Kesehatan Masyarakat, Universitas Indonesia, Depok \\ ${ }^{3}$ Pusat Kajian Ekonomi dan Kebijakan Kesehatan, Universitas Indonesia, Depok
}

Korespondensi: Masykur Alawi

e-mail: masykuralawi79@gmail.com

\begin{abstract}
Abstrak
Puskesmas sebagai garda terdepan dalam pelayanan kesehatan dasar diharuskan menuntaskan kasus-kasus non spesialistik. Namun, data laporan BPJS Kesehatan pada tahun 2015 menunjukkaan adanya 11.487 rujukan kasus non spesialistik dari 58 Puskesmas di Kabupaten Sukabumi. Tujuan penelitian ini adalah mengetahui faktor-faktor yang berhubungan dengan tingginya rujukan kasus non spesialistik pasien JKN pada puskesmas di Kabupaten Sukabumi tahun 2015. Penelitian menggunakan desain cross sectional, pada sampel 58 Puskesmas dengan satu orang dokter dari setiap Puskesmas dengan menggunakan whole sampling. Hasil analisis data didapatkan ada hubungan antara wilayah (nilai $p=0,000$ ); kecukupan obat (nilai $p=0,040$ ); kecukupan alat kesehatan (nilai $p=0,024$ ) dan jarak puskesmas (nilai $p=0,003$ ) dengan rujukan kasus non spesialistik. Perlu adanya pemenuhan obat-obatan, alat kesehatan sesuai standar Puskesmas dan monitoring dan evaluasi rujukan kasus non spesialistik dari Puskesmas dan BPJS Kesehatan.
\end{abstract}

Kata Kunci: Puskesmas; rujukan kasus non spesialistik; JKN

\begin{abstract}
Public Health Center is the frontline in the basic health services that include non-specialist cases to be solved in this primary health care level. However, a report from BPJS Kesehatan in 2015 showed that there were 11.487 referral of non-specialist cases in Primary Health Cares (PHCS) in Sukabumi. This study was to determine factors associated with high referral rate of National Health Insurance's members with non-specialist cases by PHCs in Sukabumi in 2015. The study employed cross-sectional design in 58 PHCs along with a general practitioner in each centers using a whole sampling. The result showed that there were correlation between characteristics of the region ( $P=0,000)$; adequacy of drug $(P=0,040)$; adequacy of medical devices $(P=0,024)$; and distance from the PHCs to the referral health care facilities ( $P=0,003$ ) with non-specialist cases referral rate. It is recommended for the PHCs to meet the needs of drugs, medical devices according to the standard, monitor and evaluate the non-specialist referral cases, both from health centers and the Social Security Agency for Health of Sukabumi.
\end{abstract}

Keywords: Public Health Center; referral of cases of non-specialist; National Health Insurance

\section{Pendahuluan}

Fasilitas Kesehatan Tingkat Pertama (FKTP) sebagai gatekeeper di era JKN wajib memberikan pelayanan primer yang komprehensif dengan pelayanan kesehatan yang berkualitas. Program Jaminan Kesehatan Nasional (JKN) telah membuat akses terhadap pelayanan kesehatan semakin terbuka dan meningkatkan utilisasi. Di era JKN, pelayanan kesehatan menggunakan sistem rujukan berjenjang dengan pembagian tugas dan fungsi dari setiap penyedia pelayanan kesehatan. Deklarasi Alma Ata (1978) tentang konsep Primary Health Care (PHC) menjelaskan bahwa dibutuhkan dukungan ketersediaan mutu pelayanan kesehatan. Konsep gatekeeper menurut WHO (2008) dijelaskan bahwa managed care memerlukan ketersediaan dan perbaikan mutu supply side BPJS Kesehatan.

Dalam konsep gatekeeper, FKTP berperan sebagai pemberi pelayanan kesehatan dasar berfungsi optimal sesuai standar kompetensinya dan memberikan pelayanan kesehatan sesuai standar pelayanan medik. Tujuan lain gatekeeper adalah mengoptimalkan fungsi fasilitas kesehatan dalam memberikan pelayanan kesehatan sesuai dengan standar kompetensinya, 
meningkatkan kualitas pelayanan kesehatan di Fasiltias Kesehatan Tingkat Lanjutan (FKTL), melakukan penapisan pelayanan yang perlu dirujuk, menata sistem rujukan dan meningkatkan kepuasan peserta dengan memberikan pelayanan kesehatan yang berkualitas.

Kabupaten Sukabumi sebagai Kabupten terluas sepulau Jawa dan Bali secara wilayah seharusnya sudah bisa mengimplementasikan sistem rujukan dan menangani kasus-kasus non spesialistik di Puskesmas. Namun, pada saat ini masih belum sesuai dengan harapan. Tingginya kasus-kasus non spesialistik yang dirujuk dari Puskesmas ke Rumah Sakit menunjukan belum optimalnya fungsi Puskesmas sebagai gatekeeper.

Data rujukan non spesialistik BPJS bidang kesehatan dari Januari sampai September tahun 2015 di Kabupaten Sukabumi menunjukan dari 58 Puskesmas yang ada terdapat 11.487 kasus rujukan non spesialistik (BPJS Cabang Sukabumi, 2015). Oleh karena itu, penelitian ini dilakukan untuk mengetahui faktor-faktor yang berhubungan dengan tingginya rujukan pasien JKN dengan kasus-kasus non spesialistik oleh Puskesmas di Kabupaten Sukabumi selama tahun 2015

\section{Metodologi Penelitian}

Desain penelitian ini menggunakan pendekatan cross sectional dengan sumber data penelitian menggunakan data primer dan sekunder, hal ini bertujuan untuk saling melengkapi dan memperkuat data penelitian. Pelaksanaan penelitian dilakukan dengan cara penyebaran kuesioner pada 58 Puskesmas dengan satu orang dokter dari setiap Puskesmas dengan menggunakan whole sampling dan dengan penelusuran dokumen terkait.

\section{Hasil Penelitian}

Tabel 1 menunjukkan hubungan antara jarak puskesmas terhadap pelayanan kesehatan rujukan (nilai $p=0,003)$. Hal ini memperlihatkan bahwa keputusan dokter untuk merujuk kasus-kasus non spesialistik dipengaruhi oleh jarak antara puskesmas dan FKRTL. Tabel 2 menunjukkan hubungan antara variabel independen dengan variabel dependen. Variabel kategori puskesmas berdasarkan wilayah (nilai $\mathrm{p}=0,000$ ); kecukupan obat (nilai $\mathrm{p}=0,040$ ) dan kecukupan alat kesehatan (nilai $\mathrm{p}=0,024$ ) memiliki hubungan bermakna dengan tingginya rujukan kasus non spesialistik. Untuk variabel keteraturan distribusi obat, semua Puskesmas menyatakan distribusi obat teratur dari Dinas Kesehatan selama tahun 2015, hal ini membuat variabel distribusi obat tidak bisa dianalisa.

\section{Pembahasan}

\section{Status Kepegawain Dokter Puskesmas.}

Menurut Undang-Undang Aparatur Sipil Negara (ASN) No. 5 tahun 2014 bahwa ada dua status kepegawaian dalam ASN yaitu Pegawai Negeri Sipil (PNS) dan Pegawai Pemerintah dengan Perjanjian Kerja (PPPK). Sedangkan di Kabupaten Sukabumi khususnya di lingkup Dinas Kesehatan terdapat dua kategori status kepegawaian yaitu PNS dan non PNS. Non PNS terdiri dari Pegawai Tidak Tetap (PTT) Pusat dan Provinsi serta Pegawai Harian Lepas. Hasil dari penelitian menyatakan bahwa tidak ada hubungan antara status kepegawaian dokter Puskesmas dengan tingginya rujukan kasus non spesialistik. Hal ini menunjukan bahwa baik dokter yang berstatus PNS maupun dokter yang berstatus non PNS tidak berdampak terhadap rujukan.

Tabel 1. Lama kerja, jarak dan hari pelayanan terhadap jumlah kasus rujukan non spesialistik di puskesmas di wilayah Kabupaten Sukabumi (menggunkan uji mann-whitney)

\begin{tabular}{|c|c|c|c|c|c|}
\hline Variabel & $\begin{array}{l}\text { Rujukan } \\
\text { kasus non } \\
\text { spesialistik }\end{array}$ & $\mathbf{N}$ & Mean & Mean Diff & $P$ value \\
\hline \multirow[t]{2}{*}{ Lama Bekerja } & Tinggi & 17 & 32,3 & \multirow{2}{*}{4} & \multirow{2}{*}{0,408} \\
\hline & Rendah & 41 & 28,3 & & \\
\hline \multirow[t]{2}{*}{ Jarak } & Tinggi & 17 & 19,2 & \multirow{2}{*}{14,6} & \multirow{2}{*}{$0,003 * *$} \\
\hline & Rendah & 41 & 33,8 & & \\
\hline \multirow[t]{2}{*}{ Hari Pelayanan } & Tinggi & 17 & 31,1 & \multirow{2}{*}{3,8} & \multirow{2}{*}{0,632} \\
\hline & Rendah & 41 & 28.9 & & \\
\hline
\end{tabular}

**= bermakna signifikan secara statistik $(\mathrm{p}$-value $<0,01)$ 
Tabel 2. Hasil Uji Beda Proporsi Faktor yang Mempengaruhi Rujukan Kasus non Spesialistik di Puskesmas Kabupaten Sukabumi tahun 2015

\begin{tabular}{|c|c|c|c|c|c|}
\hline \multirow[b]{2}{*}{ No } & \multirow[b]{2}{*}{ Variabel } & \multicolumn{2}{|c|}{ Rujukan } & \multirow[b]{2}{*}{$P$ value } & \multirow[b]{2}{*}{ Coef Correlatior } \\
\hline & & $\begin{array}{l}\text { Tinggi } \\
\text { F (\%) }\end{array}$ & $\begin{array}{c}\text { Rendah } \\
\text { F (\%) }\end{array}$ & & \\
\hline 1 & $\begin{array}{l}\text { Status Kepegawaian } \\
\text { PNS } \\
\text { Non PNS }\end{array}$ & $\begin{array}{l}15(30,6) \\
2(22,2)\end{array}$ & $\begin{array}{c}34(69,4) \\
7(77,8)\end{array}$ & 0,473 & 0,067 \\
\hline 2 & $\begin{array}{l}\text { Kategori Puskesmas berdasarkan } \\
\text { Wilayah } \\
\text { Perkotaan } \\
\text { Pedesaan }\end{array}$ & $\begin{array}{l}9(81,8) \\
8(17,0)\end{array}$ & $\begin{array}{c}2(18,2) \\
39(83,0)\end{array}$ & $0,000^{\star *}$ & 0,487 \\
\hline 3 & $\begin{array}{l}\text { Kategori puskesmas berdasarkan } \\
\text { Penyelenggaraan } \\
\text { DTP } \\
\text { Non DTP }\end{array}$ & $\begin{array}{c}2(33,3) \\
15(28,8)\end{array}$ & $\begin{array}{c}4(66,7) \\
37(71,2)\end{array}$ & 0,819 & 0,030 \\
\hline 4 & $\begin{array}{l}\text { Kecukupan Obat } \\
\text { Kurang } \\
\text { Cukup }\end{array}$ & $\begin{array}{c}14(38,9) \\
3(13,6)\end{array}$ & $\begin{array}{l}22(61,1) \\
19(86,4)\end{array}$ & $0,040^{*}$ & 0,260 \\
\hline 5 & $\begin{array}{l}\text { Kecukupan Alat Kesehatan } \\
\text { Kurang } \\
\text { Cukup }\end{array}$ & $\begin{array}{c}13(41,9) \\
4(14,8)\end{array}$ & $\begin{array}{l}18(58,1) \\
23(85,2)\end{array}$ & $0,024^{*}$ & 0,285 \\
\hline 6 & $\begin{array}{l}\text { Distribusi Obat } \\
\text { Teratur } \\
\text { Tidak teratur }\end{array}$ & $\begin{array}{c}17(29,3) \\
0\end{array}$ & $\begin{array}{c}41(70,7) \\
0\end{array}$ & - & - \\
\hline 7 & $\begin{array}{l}\text { Pengetahuan Dokter tentang Gate } \\
\text { keeper } \\
\text { Kurang } \\
\text { Baik } \\
\end{array}$ & $\begin{array}{c}6(61,5) \\
9(20) \\
\end{array}$ & $\begin{array}{l}5(38,5) \\
36(80) \\
\end{array}$ & 0,171 & 0,195 \\
\hline 8 & $\begin{array}{l}\text { Pengetahuan Dokter tentang Ka- } \\
\text { sus Non Spesialistik } \\
\text { Kurang } \\
\text { Baik }\end{array}$ & $\begin{array}{c}4(33,3) \\
13(28,3)\end{array}$ & $\begin{array}{c}8(66,7) \\
33(71,7)\end{array}$ & 0,733 & 0,045 \\
\hline 9 & $\begin{array}{l}\text { Pengetahuan Dokter tentang } \\
\text { Sistem rujukan } \\
\text { Kurang } \\
\text { Baik } \\
\end{array}$ & $\begin{array}{c}5(45,5) \\
12(25,5) \\
\end{array}$ & $\begin{array}{c}6(54,5) \\
35(74,5) \\
\end{array}$ & 0,270 & 0,169 \\
\hline 10 & $\begin{array}{l}\text { Tanggung jawab dokter } \\
\text { Kurang } \\
\text { Baik }\end{array}$ & $\begin{array}{c}5(41,7) \\
12(26,1)\end{array}$ & $\begin{array}{c}7(58,3) \\
34(73,9)\end{array}$ & 0,307 & 0,137 \\
\hline
\end{tabular}

Gibson (1987) berpendapat bahwa karakteristik individu (umur, jenis kelamin, lama kerja, status perkawinan dan status pekerjaan) berpengaruh terhadap kinerja pegawai. Tingginya rujukan kasus non spesialistik yang dilakukan oleh dokter Puskesmas menunjukan kinerja dan komitmen dokter tersebut dalam mentaati peraturan dan kewajibannya di Puskesmas. Hasil penelitian ini berbanding terbalik dengan sejumlah penelitian yang menunjukkan bahwa status kepegawaian seseorang dapat mempengaruhi komitmen organisasionalnya. Penelitian Seong (2011) pada sekitar 1000 pekerja dari berbagai sektor di Korea menemukan bahwa tingkat komitmen organisasional setiap karyawan bervariasi dipengaruhi oleh status kepegawaian mereka. Status kepegawaian yang lebih terjamin dapat memperkuat komitmen organisasi pegawai tersebut.

David Biggs (2006) dalam penelitiannya menyatakan bahwa status kepegawaian juga dapat mempengaruhi komitmen seseorang dalam organisasi, 
yang menunjukkan bahwa terdapat perbedaan level komitmen organisasional antara pegawai kontrak dan pegawai tetap (Wirakusuma, I. Nyoman, 2015). Sedangkan penelitian Husna, Arfah, and Besral tentang Kinerja Bidan di Desa dalam program Jaminan Pemeliharaan Kesehatan Masyarakat miskin menyatakan tidak ada hubungan antara status kepegawaian dengan kinerja.

\section{Kategori Puskesmas berdasarkan wilayah}

Hasil penelitian menyatakan bahwa terdapat hubungan yang signifikan antar Puskesmas wilayah perkotaan dengan Puskesmas wilayah pedesaan dengan tingginya rujukan kasus non spesialistik dengan $\mathrm{P}$ value 0,00. Dari data tersebut dan dikorelasikan dengan hasil penelitian yang menyatakan wilayah perkotaan lebih banyak merujuk kasus non spesialistik, maka dapat disimpulkan bahwa banyaknya fasilitas rujukan mempengaruhi dokter maupun pasien untuk memanfaatkan fasilitas rujukan.

Daerah pedesaan akan lebih sulit menjangkau fasilitas rujukan, hal ini diperkuat dengan pendapat Abbas Syafriadi, Kusnanto dan Lazuardi (2008) yang menyatakan bahwa faktor keterpencilan dan mahalnya transportasi merupakan hambatan untuk menjangkau sarana kesehatan. Nurcahyani (2000) menyebutkan adanya hubungan antara biaya berobat, biaya transportasi, jarak dan lama waktu terhadap pemanfaatan pelayanan.

\section{Kategori Puskesmas berdasarkan kemampuan penyelenggaraan}

Berdasarkan Peraturan Menteri Kesehatan no 75 tahun 2014, Puskesmas dibagi menjadi Puskesmas Dengan Tempat Tidur (DTP) dan Puskesmas Non DTP. Puskesmas perawatan atau puskesmas rawat inap adalah puskesmas yang diberi tambahan ruangan dan fasilitas untuk menolong pasien gawat darurat, baik berupa tindakan operatif terbatas maupun rawat inap sementara (Effendi, 2009). Hasil penelitian menyatakan bahwa tidak ada hubungan antara kategori Puskesmas berdasarkan kemampuan penyelenggaraan dengan tingginya rujukan kasus non spesialistik. Dari hasil ini dapat disimpulkan bahwa rujukan kasus non spesilistik tidak berpengaruh dengan ada atau tidaknya Puskesmas DTP di wilayah.

Idealnya ketika di wilayah sudah terdapat Puskesmas perawatan maka sudah tidak ada lagi rujukan kasus non spesialistik ke fasilitas rujukan. Namun hasil penelitian ini menunjukan Puskesmas DTP masih melakukan rujukan, hal ini dikarenakan dokter yang melakukan rujukan atau masyarakat lebih memilih memanfaatkan fasilitas rujukan. Belum optimalnya pemanfaatan puskesmas disebabkan masih rendahnya kepercayaan masyarakat terhadap puskesmas. Menurut Wibowo (2010) stigma adalah ciri negatif yang menempel pada pribadi seseorang karena pengaruh lingkungannya, Sedangkan stigma pelayanan kesehatan adalah anggapan buruk/negatif yang diterima oleh individu terkait hal yang berhubungan dengan pelayanan kesehatan khususnya Puskesmas.

\section{Kecukupan obat}

Hasil penelitian menyatakan kecukupan obat untuk menanggulangi kasus non spesialistik di Puskesmas berpengaruh terhadap tingginya rujukan. Hal ini sejalan dengan penelitian Zuhrawardi (2007) terkait analisis pelaksanaan rujukan rawat jalan tingkat pertama peserta wajib PT Askes pada tiga puskesmas di Kota Aceh. Hasil penelitian yaitu sekitar 30-75\% rujukan adalah rujukan rawat jalan tingkat pertama yang dilakukan atas permintaannya/keluarga pasien dan bukan atas indikasi medis. Beberapa alasan yang dikemukakan adalah para pasien merasa kecewa dengan obat-obatan yang disediakan di puskesmas.

Di Era JKN, Puskesmas di Kabupaten Sukabumi baru menerima obat dengan sumber dana JKN pada tahun 2015. Obat tersebut dialokasikan dari dana luncuran JKN Januari sampai dengan April 2014, sehingga penanggulangan kasus non spesialistik pasien JKN dilayani dengan obat umum. Ketersediaan obatobatan mengacu pada KMK Nomor 159/Menkes/ SK/V/2014 atas perubahan KMK Nomor 328/Menkes/IX/2013 tentang Formularium Nasional. Ketersediaan obat-obatan harus berdasarkan formularium nasional yang telah ditetapkan oleh BPJS Kesehatan.

Sebagian besar sampel yaitu 36 Puskesmas (62,1 \%) menyatakan kekurangan obat selama tahun 2015 untuk melayani dan menanggulangi kasus non spesialistik. Hal ini cukup mendasar karena masih belum tersedianya obat JKN dikarenakan belum adanya kesepahaman dalam menafsirkan aturan dalam pengadaan obat, masih adanya ketakutan perbuatan melawan hukum dalam pengadaan obat dan keterbatasan pejabat pengadaan obat di Puskesmas. Adanya hubungan antara kekurangan obat di Puskesmas dengan tingginya rujukan kasus non spesialistik menunjukan bahwa dokter sebagai provider maupun pasien akan memilih untuk memanfaatkan Fasilitas rujukan yang memiliki kecukupan obat.

\section{Kecukupan alat kesehatan}

Hasil penelitian menyatakan ada hubungan antara kecukupan alat kesehatan di Puskesmas dengan tingginya rujukan kasus non spesialistik dengan nilai $\mathrm{P}$ value 0,024 dengan coef correlation 0,285. Penelitian 
ini sejalan dengan hasil penelitian yang dilakukan oleh Kesumawati (2012) bahwa ketersediaan fasilitas alat kesehatan mempengaruhi pelaksanaan sistem rujukan. Begitu pentingnya alat kesehatan yang harus ada di Puskesmas karena fungsinya sangat erat dengan tugas dokter dalam mencegah, mendiagnosis, menyembuhkan dan meringankan penyakit, merawat orang sakit, memulihkan kesehatan pada manusia, dan/atau membentuk struktur dan memperbaiki fungsi tubuh. Ketiadaan atau kekurangan alat kesehatan akan mengurangi dan menghambat tugas dokter dalam melaksanakan pekerjaannya.

\section{Keteraturan distribusi obat.}

Hasil penelitian menunjukan semua responden 58 Puskesmas (100\%) menyatakan distribusi obat selama tahun 2015 sesuai dengan jadwal distribusi. Mayoritas Puskesmas $71 \%$ ada di kategori rendah dalam melakukan rujukan kasus non spesialistik karena seluruh Puskesmas menyatakan distribusi obat sudah dilakukan dengan teratur maka analisis tidak dapat dilakukan. Setelah dilakukan konfirmasi dengan UPTD Gudang farmasi Kabupaten Sukabumi yang bertanggung jawab terhadap penyaluran obat menyatakan distribusi obat sudah teratur dan rutin. Ada obat-obat esensial didistribusikan setiap bulan dan ada obat non esensial didistribusikan setiap triwulan. Meskipun distribusi obat sudah teratur, tetapi tidak dipungkiri bahwa di Puskesmas masih kekurangan obat dikarenakan permintaannya tidak sesuai dengan yang didistribusikan.

\section{Pengetahuan dokter Puskesmas tentang Gate keeper}

Hasil penelitian menunjukan mayoritas dokter Puskesmas berpengetahuan baik yaitu berjumlah 45 orang $(77,6 \%)$. Hasil penelitian ini sama dengan penelitian yang dilakukan Ali (2015) bahwa pemahaman petugas sebagi pintu masuk atau penapis rujukan (gate keeper) di kota Ternate cukup baik, namun hasil penelitian menunjukan tidak ada hubungan antara pengetahuan dokter Puskesmas dengan tingginya rujukan kasus non spesialistik yang ditunjukan (nilai $\mathrm{p}=0,171$ ). Dokter diharuskan mengetahui konsep gatekeeper untuk melaksanakan pelayanan tingkat pertama yang berkualitas sehingga dapat menanggulangi kasus-kasus non spesialistik di Puskesmas. Idealnya jika dokter mengetahui konsep gatekeeper dengan baik maka berdampak terhadap rendahnya atau tidak ada rujukan kasus non spesialistik ke rumah sakit.

\section{Pengetahuan dokter Puskesmas tentang Kasus non spesialistik}

Kasus non spesialistik adalah 144 kasus atau diagno- sa non spesialistik yang harus ditangani di Puskesmas. Setelah dilakukan analisis dengan uji chi-square tidak ada hubungan antara pengetahuan dokter tentang kasus non spesialistik dan rujukan kasus non spesialistik, hal ini ditunjukan oleh p value 0,733.

Tabel 3. Pengetahuan dokter tentang kasus non spesialistik

\begin{tabular}{cccc}
\hline & & \multicolumn{2}{c}{ Rujukan non spesialistik } \\
\cline { 3 - 4 } & & Tinggi & Rendah \\
\hline $\begin{array}{c}\text { Pengetahuan } \\
\text { Dokter }\end{array}$ & Baik & $28,3 \%$ & $71,7 \%$ \\
& Kurang & $33,3 \%$ & $66,7 \%$ \\
\hline
\end{tabular}

Hal ini bertentangan dengan hasil penelitian Cloyd (1997) yaitu besarnya usaha (proksi dari variabel akuntabilitas) yang dicurahkan seseorang untuk menyelesaikan sebuah pekerjaan berbeda-beda sesuai dengan tingkat pengetahuan yang dimiliki. Cloyd (1997) juga menemukan bahwa tingkat pengetahuan seseorang dapat meningkatkan kualitas hasil kerja.

\section{Pengetahuan dokter Puskesmas tentang sistem rujukan}

Sistem rujukan pelayanan kesehatan adalah penyelenggaraan pelayanan kesehatan yang mengatur pelimpahan tugas dan tanggung jawab pelayanan kesehatan secara timbal balik baik vertikal maupun horizontal yang wajib dilaksanakan oleh peserta jaminan kesehatan dan seluruh fasilitas kesehatan (Kemenkes RI, 2013). Pengetahuan dokter Puskesmas tentang sistem rujukan sangat penting dalam mengimplementasikan rujukan berjenjang sesuai dengan ketentuan.

Tabel 4. Pengetahuan dokter tentang sistem rujukan

\begin{tabular}{cccc}
\hline & & \multicolumn{2}{c}{ Sistem Rujukan } \\
\cline { 3 - 4 } & & Tinggi & Rendah \\
\hline $\begin{array}{c}\text { Pengetahuan } \\
\text { Dokter }\end{array}$ & Baik & $25,5 \%$ & $74,5 \%$ \\
& Kurang & $45,5 \%$ & $54,5 \%$ \\
\hline
\end{tabular}

Setelah dianalisa dengan uji chi-square tidak ada hubungan antara pengetahuan dokter tentang konsep gatekeeper dan rujukan kasus non spesialistik, hal ini ditunjukan oleh p value 0,270.

Tanggung jawab dokter Puskesmas

Hasil analisis bivariat dengan uji chi-square dihasilkan tidak ada hubungan antara pengetahuan dokter 
tentang konsep gatekeeper dan rujukan kasus non spesialistik, hal ini ditunjukan oleh p value 0,307. Kenyataan di lapangan bentuk dari tanggung jawab dokter sebagai penanggung jawab medis adalah ketika dia tidak bisa melayani pasien di Puskesmas, dokter yang bersangkutan mendelegasikan kewenangannya kepada petugas lain yang ada di Puskesmas (petugas yang berkompeten). Bentuk lain dari tanggung jawab dokter adalah memberikan pengetahauan (transfer knowledge) terhadap petugas lain terutama paramedis tentang pengobatan dasar dan hal-hal lainnya sebagai bekal dalam melakukan fungsi kolaborasi.

Tabel 5. Tanggung Jawab dokter dengan rujukan non spesialistik

\begin{tabular}{cccc}
\hline & & \multicolumn{2}{c}{$\begin{array}{c}\text { Rujukan non } \\
\text { spesialistik }\end{array}$} \\
\cline { 3 - 4 } & & Tinggi & Rendah \\
\hline $\begin{array}{c}\text { Tanggung } \\
\text { Jawab } \\
\text { Dokter }\end{array}$ & Baik & $26,1 \%$ & $73,9 \%$ \\
\hline
\end{tabular}

\section{Lama bekerja/ masa kerja dokter Puskesmas}

Hasil penelitian menyatakan bahwa lama bekerja tidak berpengaruh terhadap rujukan kasus non spesialistik yang ditunjukan dengan nilai p lebih dari 0,05 yaitu nilai p value 0,408 . Tinggi rendahnya rujukan kasus non spesialistik menunjukan komitmen dokter puskesmas terhadap organisasinya yaitu Puskesmas. Penelitian ini bersebrangan dengan hasil dari penelitian Steers (1977), Mathieu dan Zajac (1990), serta Dunham, Grube, dan Castaneda (1994) ditemukan bahwa: (1) karakteristik personal yang terdiri dari usia, lama kerja, jenis kelamin, dan tingkat pendidikan; (2) karakteristik pekerjaan yang terdiri dari tantangan pekerjaan, konflik peran, dan ambiguitas peran; serta (3) pengalaman kerja (terdiri dari gaya kepemimpinan, keterandalan organisasi, dan rekan kerja).

\section{Jarak Puskesmas ke Fasilitas rujukan.}

Hasil penelitian menyatakan adanya perbedaan rerata yang paling tinggi dari variabel jarak dengan p value 0,003 dan mean difference 14,6 artinya jarak puskesmas terhadap pelayanan kesehatan rujukan memiliki pengaruh terhadap keputusan dokter untuk merujuk kasus-kasus non spesialistik. Semakin dekat Puskemas dengan fasilitas rujukan maka akan semakin banyaknya rujukan kasus non spesialistik baik itu yang dilakukan oleh dokter Puskesmas maupun oleh masyarakat itu sendiri.

Menurut Stock yang dikutip Nurhayati (1999), jarak adalah satuan ukur yang memisahkan antara lokasi satu dengan lokasi yang lain. Dimana jarak memiliki pengaruh yang besar dalam memilih sebuah pelayanan kesehatan. Menurut Stock yang dikutip oleh Nurhayati (1999), faktor jarak sangat berperan dalam pemanfaatan pelayanan kesehatan. Dalam hal tingginya rujukan kasus non spesialistik di Kabupaten Sukabumi bisa disebabkan oleh lebih dekatnya Puskesmas ke fasilitas rujukan sehingga pasien lebih memilih untuk memanfaatkan layanan kesehatan di fasilitas rujukan.

Puskesmas yang ada di wilayah Kabupaten Sukabumi tersebar di 47 kecamatan dan dibagi menjadi 7 (tujuh) wilayah. Wilayah 1, 2 dan 3 mayoritas mempunyai Puskesmas dengan kategori Puskesmas perkotaan, sedangkan wilayah 4, 5, 6 dan 7 mayoritas mempunyai Puskesmas dengan kategori wilayah pedesaan. Di wilayah 1, 2 dan 3 tersebar Fasilitas Rujukan baik Rumah Sakit Daerah, Rumah Sakit Swasta maupun klinik-klinik yang bisa dijadikan rujukan, namun di wilayah 4, 5, 6 dan 7 hanya dekat dengan Rumah Sakit daerah.

Menurut Notoatmodjo (2010), rendahnya utilisasi (penggunaan) fasilitas kesehatan seperti Puskesmas, Rumah Sakit, Balai pengobatan, dan sebagainya tidak hanya disebabkan oleh faktor jarak antara fasilitas tersebut. Masyarakat yang terlalu jauh (baik jarak secara fisik maupun sosial), tarif yang tinggi, pelayanan yang tidak memuaskan dan sebagainya, tetapi juga dipengaruhi oleh faktor masyarakat itu sendiri, diantaranya persepsi atau konsep dari masyarakat.

\section{Keberadaan Dokter di Puskesmas/Hari pe- layanan}

Hari pelayanan adalah jumlah hari kerja efektif dalam satu tahun dan dokter Puskesmas melayani pasien di Puskesmas. Berdasarkan hasil penelitian tidak ada hubungan antara jumlah hari pelayanan dokter dengan rujukan kasus non spesialistik yang dibuktikan dengan nilai p value 0,632. Keberadaan dokter di Puskesmas untuk melayani dan menanggulangi kasus-kasus non spesialistik di Puskesmas sangat penting dan sangat vital, karena dokterlah yang menjadi ujung tombak sekaligus penanggung jawab pelayanan kuratif sehingga tidak ada lagi kasus non spesialitik yang dirujuk ke fasilitas rujukan. Idealnya semakin banyak waktu dokter di Puskesmas untuk melayani pasien maka akan semakin sedikit kemungkinan kasus non spesialistik dirujuk, namun sebaliknya semakin sedikit waktu dokter di Puskesmas maka kemungkinan akan semakin banyak atau tinggi kasus rujukan kasus non spesialistik. 


\section{Kesimpulan dan Saran \\ Kesimpulan}

Faktor-faktor yang berhubungan dengan tingginya rujukan kasus non spesialistik pasien jaminan kesehatan nasional di puskesmas kabupaten Sukabumi tahun 2015 adalah kategori puskesmas berdasarkan wilayah, kecukupan obat dan kecukupan alat kesehatan di puskesmas serta jarak puskesmas ke fasilitas rujukan.

\section{Saran}

BPJS harus melakukan monitoring dan evaluasi terhadap puskesmas dalam pelaksanaan sistem rujukan, pelaksanaan laporan dan P-care. Puskesmas harus berkoordinasi dengan Dinas Kesehatan dalam pemenuhan sarana dan prasarana termasuk obatobatan.

\section{Daftar Pustaka}

Ali, Fauziah Abdullah. 2015. Analisis Pelaksanaan Rujukan Rawat Jalan Tingkat Pertama Peserta Program Jaminan Kesehatan Nasional (JKN) Di Puskesmas Siko Dan Puskesmas Kalumata Kota Ternate Tahun 2014. JIKMU, 5.3.

BPJS Kesehatan. 2013. Panduan Praktis Gatekeeper Concept Fasilitas Kesehatan BPJS Kesehatan.

BPJS Kesehatan. 2014. Panduan Praktis Sistem Rujukan Berjenjang. 2014.

Dinas Kesehatan Kabupaten Sukabumi. 2015. Profil Dinas Kesehatan Kabupaten Sukabumi tahun 2015.

Gani, Ascobat.1998.Asuransi Kesehatan dan Manfaatnya Bagi Masyarakat, Fakultas Kesehatan Masyarakat, Universitas Indonesia.

Hastono, S. P. 2014. Manajemen dan Analisa Data Kesehatan, Departemen Biostatistik Fakultas Kesehatan Masyarakat, Universitas Indonesia

Kemenkes RI. 2014. Pedoman Pelaksanaan Program Jaminan Kesehatan Nasional.

Kemenkes RI. 2014. Peraturan Menteri Kesehatan Republik Indonesia Nomor 28 Tahun 2014 Tentang Pedoman Pelaksanaan Program Jaminan Kesehatan Nasional.

Kemenkes RI. 2013.Peraturan Menteri Kesehatan Republik Indonesia Nomor 71 Tahun 2013
Tentang Pelayanan Kesehatan Pada Jaminan Kesehatan Nasional.

Kemenkes RI. 2014.Peraturan Menteri Kesehatan Republik Indonesia Nomor 75 Tahun 2014 Tentang Pusat Kesehatan Masyarakat.

Kesumawati. 2012.Analisis pelaksanaan rujukan rawat jalan tingkat pertama peserta Askes Sosial PT Askes kantor cabang Sukabumi tahun 2012.

Konsil Kedokteran Indonesia. 2012.Standar Kompetensi Dokter Indonesia Edisi Kedua, 2012 Cetakan Pertama, Desember 2012.

Lwanga, S. \& Lemeshow, S.1997. Sample Size Determination in Health Studies, Jenewa: WHO.

Menkumham R. 2013.Peraturan Presiden Republik Indonesia Nomor 12 Tahun 2013 Tentang Jaminan Kesehatan.

Nazriati, Elda, Husnedi, Nuzelly. Profil Rujukan Kasus Nonspesifik pada Fasilitas Kesehatan Tingkat Primer. Kesmas: Jurnal Kesehatan Masyarakat Nasional, 2015, 9.4: 327-332.

Notoatmojo. 1993.Metodologi Penelitian Kesehatan, Penerbit Rineka Cipta, Jakarta. Besar dan Metode Sampel pada Penelitian Kesehatan, Fakultas Kesehatan Masyarakat, Universitas Indonesia.

Sabardianto, Tjatur Djoko. 2008. Analisis pemanfaatan fasilitas kesehatan oleh pengguna jasa berdasarkan aksesbilitas pada puskesmas kecamatan di wilayah jakarta pusat

Saifuddin Azwar. 2004. Metode Penelitian, Cetakan V, Pustaka Pelajar, Yogyakarta.

Sulastomo. 1999.Asuransi Kesehatan, Konsep Dasar dan Perkembangannya, Penerbit PT (Persero) Asuransi Kesehatan Indonesia, Jakarta.

Sulastomo. 2000.Pembiayaan Kesehatan Dari Asuransi ke Managed Care Concept, cetakan pertama, penerbit PT. Asuransi Kesehatan Indonesia, Jakarta, Januari.

Thabrani, Hasbullah. 1998. Pembayaran Kapitasi, asuransi Kesehatan, JPKM, Managed Care, Badan Penerbit FKM UI 